\section{Comparison of mor- phine and morphine with ketamine for postoperative analgesia}

Keith B. Javery DO, Todd W. Ussery MD, Herbert G. Steger PhD, George W. Colclough MD
Purpose: The purpose of this study was to compare morphine with ketamine to morphine alone in a double-blind investigation of postsurgical pain control.

Methods: Forty-two ASA 1 and 2 patients undergoing elective microdiscectomy were administered either $1 \mathrm{mg} \cdot \mathrm{ml}^{-1}$ of morphine $(n=20)$ or $1 \mathrm{mg} \cdot \mathrm{ml}^{-1}$ of both morphine and ketamine $(n=22)$ via iv patient controlled analgesia (IVPCA). Pain relief and side effects were assessed at $24 \mathrm{hr}$ after surgery.

Results: The mean (SD) visual analogue scale (VAS) pain rating of 2.3 (1.67) for patients receiving morphine with ketamine was lower $(P<0.001)$ than the VAS scores of patients receiving only morphine 4.5 (1.54). Patients receiving morphine and ketamine also had less difficulty with side effects, reporting less nausea $(P<0.05)$, pruritus $(P<0.001)$, and urinary retention $(P<0.05)$. Although dysphoria is reported to be a common side effect of ketamine, complaints of dysphoria were rare in both groups, with only one subject (5\%) in the morphine with ketamine group and three (15\%) subjects receiving morphine alone reporting this side effect.

Conclusion: IVPCA ketamine in combination with morphine provides superior postsurgical pain relief at lower dosage and with fewer side effects than morphine alone.

Objectif: Cette étude en double aveugle visait à comparer la kétamine associée à la morphine avec la morphine seule utilisée dans le but de traiter la douleur postopératoire.

Méthode: Quarante-deux patients ASA 1 et 2 programmés pour une microdiscoïdectomie ont reçu $1 \mathrm{mg} \cdot \mathrm{ml}^{-1}$ de morphine $(n=10)$ ou $1 \mathrm{mg} \cdot \mathrm{ml}^{-1}$ à la fois de morphine et de kéta-

\section{Key words}

ANALGESIA: postoperative;

ANALGESICS: ketamine, morphine;

SURGERY: orthopaedic.

From the Department of Anesthesiology, University of Kentucky College of Medicine.

Address correspondence to: Dr. Keith B. Javery, Department of Anesthesiology, University of Kentucky Medical Center, 800 Rose Street, N-202, Lexington, KY 40536-0084 U.S.A.

Accepted for publication 8th September, 1995. mine iv ( $n=22$ ) par un dispositif d'analgésie autocontrôlée $(P C A I V)$. Le soulagement et les effets secondaires ont été évalués 24 h après la chirurgie.

Résultats: La moyenne (ET) de la valeur déterminée sur une échelle visuelle analogique (EVA) de $2,3(1,67)$ pour les patients qui avaient reçu morphine-kétamine était plus basse $(P<0,001)$ que celle des patients sous morphine 4,5 $(1,54)$. Les patients sous morphine-kétamine ont eu aussi moins d'effets secondaires dont moins de nausée $(P<0,05)$, de prurit $(P$ $<0,001)$, et de rétention urinaire $(P<0,05)$. Bien que la dysphorie soit un effet secondaire fréquent de la kétamine, elle a été rarement rapportée dans les deux groupes, avec un seul sujet (5\%) du groupe morphine-kétamine et trois du groupe morphine seule (15\%).

Conclusion: En PCAIV, la kétamine associée à la morphine procure une soulagement postopératoire de la douleur à des doses plus faibles et avec moins d'effets secondaires que la morphine seule.

Intravenous morphine is commonly used as an analgesic in the postoperative period for major surgery and is the standard by which all other analgesics are gauged. Ketamine has been used as an intravenous anaesthetic. The reported $E_{50}$ for the abolition of response to painful stimulation is $1.3 \mathrm{mg} \cdot \mathrm{kg}^{-1}{ }^{1}$ Ketamine has also been used in sub-anaesthetic doses as an analgesic for both acute and chronic pain relief. ${ }^{2-5}$ The analgesic effects of ketamine occur at plasma concentrations between 100 and $150 \mathrm{ng} \cdot \mathrm{ml}^{-1}$. These concentrations have been achieved by infusions as low as 3 to 4 $\mu \mathrm{g} \cdot \mathrm{kg}^{-1} \cdot \mathrm{min}^{-1}$ after an initial loading dose. ${ }^{6}$ Successful analgesia without an initial loading bolus has been reported with infusions of $14 \mu \mathrm{g} \cdot \mathrm{kg}^{-1} \cdot \mathrm{min}^{-1}$.

Ketamine has many desirable qualities as an analgesic. It does not suppress cardiovascular function in the presence of an intact nervous system; ${ }^{7}$ it does not depress the laryngeal protective reflexes; ${ }^{8}$ it depresses ventilation less than opioid or nonopioid anaesthetic agents; ${ }^{9}$ and it may stimulate respiration. ${ }^{10}$ Decreased airway resistance has been reported in patients with reactive airway disease after ketamine administration. ${ }^{11}$ 
Adverse side effects associated with sub-anaesthetic doses of ketamine include tolerance, ${ }^{12}$ accumulation of metabolites, ${ }^{13}$ postoperative malaise, ${ }^{14}$ and cardiovascular excitation. One of the most disconcerting side effects of ketamine is its adverse psychomimetic effects, including dizziness, frightening dreams, depersonalization, and hallucinations. These reactions appear to be more common in adults than in children ${ }^{15}$ and in women than in men. ${ }^{16}$

The combination of morphine and ketamine iv has been studied with varied results. Some authors have recommended this combination because of improved respiratory rates and less sleepiness for the same degree of analgesia. ${ }^{14}$ Others have reported increased analgesia when ketamine is added to meperidine, ${ }^{17}$ but have noted an increase in the psychomimetic effects with ketamine use. $^{18}$

The combination of low dose ketamine and morphine has been used at our institution to provide better analgesia when morphine (IVPCA) has proved to be inadequate. The combination seems to be a safe and reliable method of providing postoperative analgesia that is superior to morphine alone. The present study was undertaken to determine if the addition of sub-anaesthetic doses of ketamine to morphine delivered by IVPCA would provide better analgesia than morphine alone, and minimize untoward side effects. A PCA approach to drug administration was used to obviate the arbitrary dosing guidelines necessary with infusions. Use of PCA avoids under- or overdosing analgesic, allowing the patient to titrate the dose of opioid to achieve effective analgesia. ${ }^{19}$

\section{Methods}

Based on pilot study experience with the study's dependent measures, a total sample size of 40 was calculated as necessary to demonstrate experimental effects at an acceptable confidence level. Following approval of the University of Kentucky Medical Institutional Review Board, 42 ASA 1 and 2 patients between the ages of 21 and $55 \mathrm{yr}$ who were to undergo elective lumbar microdiscectomy gave informed consent before electing to participate in the study. Patients were randomized in a double-blind fashion to receive IVPCA consisting either of morphine $1 \mathrm{mg} \cdot \mathrm{ml}^{-1}$ or morphine with ketamine $1 \mathrm{mg} \cdot \mathrm{ml}^{-1}$ of each. BARD ambulatory IVPCA pumps were programmed to deliver $1 \mathrm{ml}$ of solution with a lockout of six minutes. No basal infusion was used.

Patients were pre-medicated in the holding area with midazolam, up to $0.05 \mathrm{mg} \cdot \mathrm{kg}^{-1} \mathrm{iv}$. No preoperative opioids or nonsteroidal medications were used. General anaesthesia was induced with thiopentone $5 \mathrm{mg} \cdot \mathrm{kg}^{-1}$ and tracheal intubation was facilitated with succinylcholine $1.5 \mathrm{mg} \cdot \mathrm{kg}^{-1}$. Patients were allowed to receive fentanyl up to $2 \mu \mathrm{g} \cdot \mathrm{kg}^{-1}$ within $20 \mathrm{~min}$ after intubation. Anaesthesia was maintained with isoflurane and $100 \%$ oxygen with vecuronium bromide for muscle relaxation during the remainder of the case. Patients were then taken to the postoperative recovery room where, upon obtaining adequate cognitive function, they were instructed on the use of the IVPCA unit and connected to the IVPCA pump. Patients were returned to their wards with the pumps fully operational. No supplemental analgesia or sedation was administered to the patients during their postsurgical hospital stay.

Data were collected $24 \mathrm{hr}$ after surgery. The volume of drug was downloaded from the IVPCA pump to a laptop computer. Visual analog scores were collected 24 hr after surgery from patients using a standard $10 \mathrm{~cm}$ VAS pain ruler that the patient could manipulate to a desired pain rating. A VAS score of 0 was defined as no pain, while 10 was defined as worst pain imaginable. Side effects of nausea, urinary retention, sedation, and pruritus were evaluated using a numerical scale from 1 to 5,1 was defined as no side effect and 5 the worst severity of side effect imaginable. If the patient could be aroused only by vigorous stimulation, a rating of 5 was tabulated for sedation. If the patient required any form of urinary catheterization, this was recorded as a 5 on the 1 to 5 urinary retention scale. In addition, the intensity of any dysphoric experience such as "bad feelings," hallucinations, nightmares, or dizziness, was recorded on a 1 to 5 dysphoria scale. Patients were instructed to scale these experiences over the previous $24 \mathrm{hr}$ period. In addition, the patient's vital signs (blood pressure, pulse rate, and respiratory rate) were recorded every four hours.

Statistical analyses of data were performed using SPSS..$^{20}$ Differences between groups were analyzed with the $t$ test. Relationships between variables were investigated using Pearson product moment correlations. A probability level of 0.05 was set for rejection of null hypotheses of no difference between the groups.

\section{Results}

Of the 42 subjects enrolled in the study, 22 were assigned to the morphine-plus-ketamine group and 20 to the morphine only group. The groups were comparable and did not differ in distribution of sex, age, or weight (Table I).

Patients who received morphine plus ketamine rated their pain as lower (mean $\pm S D ; 2.3 \pm 1.67$ ) than those receiving only morphine $(4.5 \pm 1.54)(P<0.001)$. The morphine group received almost twice as much opioid $(51.1 \pm 20.8)$ as the morphine-plus-ketamine group 
$(25.82 \pm 16.40)(P<0.001)$ at a greater hourly rate $(2.6$ $\pm 1.1)$ than did those who had ketamine added $(1.2 \pm$ $0.7)(P<0.001)$.

Patients receiving ketamine reported fewer side effects than those receiving morphine alone (Table II). They reported less nausea, pruritus, and urinary retention than the morphine group. The groups did not differ in the amount of sedation or dysphoria. No respiratory depression was seen, and there were no reports of vital sign deviations $>30 \%$ from baseline. Three subjects in the morphine group (15\%) reported some difficulty with dysphoria, compared with only one in the morphineplus-ketamine group (5\%).

The only positive correlation of side effect with dose was urinary retention (Table III). Patients receiving morphine with ketamine reported a relationship between pain VAS scores and amount of medication received ( $\mathrm{r}=0.42, P<0.05$ ) and a negative relationship between sedation and dysphoria $(\mathrm{r}=-0.74, P<0.001)$.

\section{Discussion}

Our study demonstrates that the combination of ketamine in low doses with morphine, delivered via IVPCA, provided superior pain relief at lower dosage of morphine and with fewer side effects than when using morphine alone. Our results support the conclusion that morphine plus ketamine is both a safe and an effective mixture.

Patients who received morphine plus ketamine rated their pain as lower than those receiving only morphine. This difference was substantial, considering that the morphine group self-administered almost twice as much medication. Thus, it appears that the ketamine group received superior analgesia. The morphine-plus-ketamine group administered less than half the average hourly amount of medication and had fewer problems with side effects. These findings might be explained by the lower dose of morphine administered, resulting in fewer side effects. Overall the morphine group selfadministered less opioid, perhaps due to urinary retention. This was the only side effect in which there was found to be a relationship between dose and side effect, although it was not observed in the morphine with ketamine group. The addition of ketamine has a morphine sparing effect, and, due to a relatively lower dose of self-administered drug, this group avoided urinary retention.

While the addition of ketamine to morphine does produce more potent analgesia, with a lower incidence of side effects, there may be a subtle alteration in the way the ketamine or its combination with morphine affects the relationship between pain reporting and dosing. One explanation might be related to the effect of ketamine on
TABLE I Sample characteristics for morphine and morphine-plusketamine groups

\begin{tabular}{lll}
\hline Variable & Morphine & $\begin{array}{l}\text { Morphine }+ \\
\text { Ketamine }\end{array}$ \\
\hline Sex & $88 \%$ male & $79 \%$ male \\
Age & $39.5 \pm 7.2$ & $37.3 \pm 9.9$ \\
Weight $(\mathrm{kg})$ & $83.9 \pm 10.7$ & $78.2 \pm 13.1$ \\
\hline
\end{tabular}

TABLE II Side effects reported by patients receiving morphine or morphine plus ketamine

\begin{tabular}{llll}
\hline Side effect & Morphine & $\begin{array}{l}\text { Morphine }+ \\
\text { Ketamine }\end{array}$ & $P$ \\
\hline Dysphoria & $1.85 \pm 0.366$ & $1.95 \pm 0.213$ & NS \\
Nausea & $2.20 \pm 1.196$ & $1.39 \pm 0.755$ & $<0.05$ \\
Pruritus & $1.80 \pm 0.516$ & $1.18 \pm 0.395$ & $<0.001$ \\
Sedation & $2.05 \pm 0.999$ & $1.50 \pm 1.058$ & NS \\
Urinary retention & $1.70 \pm 0.801$ & $1.14 \pm 0.640$ & $<0.05$ \\
\hline
\end{tabular}

TABLE III Correlations ( $r$ ) between dose and side effects for morphine and morphine-plus-ketamine groups

\begin{tabular}{lcclll}
\hline & \multicolumn{2}{l}{ Morphine } & & \multicolumn{2}{l}{ Morphine + Ketamine } \\
\cline { 2 - 3 } \cline { 5 - 6 } Side effect & Total dose & $\mathrm{ml} \cdot \mathrm{hr} r^{-1}$ & & Total dose & $\mathrm{ml} \cdot \mathrm{hr}^{-1}$ \\
\hline Dysphoria & 0.24 & -0.42 & & 0.28 & 0.29 \\
Nausea & -0.03 & -0.14 & & 0.08 & 0.07 \\
Pruritus & 0.01 & 0.25 & & 0.06 & 0.06 \\
Sedation & 0.02 & 0.12 & & 0.36 & 0.34 \\
Urinary retention & $0.51^{*}$ & $0.57 \dagger$ & 0.21 & 0.17 \\
\hline
\end{tabular}

$* P<0.05$.

$\dagger P<0.01$.

the thalamo-neocortical projection system. ${ }^{21}$ Ketamine depresses neurons in the cortex and thalamus, while simultaneously increasing activity in the limbic system, a phenomenon termed "functional disorganization."22 Excitation of limbic functioning combined with depression of thalamic cortical functioning could affect the patient's emotional response or evaluation of pain sensation. Thus, patients receiving ketamine may be experiencing less suffering or emotional response to a similar level of nociception or somatic pain sensation. Future studies might employ more sensitive measures of behaviour, pain, and suffering to elucidate the relationship between pain report and medication dosing.

Animal studies have demonstrated potentiation between sub-effective doses of ketamine and morphine, ${ }^{23,24}$ but this has not been demonstrated in humans. Edwards et al. ${ }^{18}$ combined an infusion of morphine and ketamine for postoperative analgesia in elderly patients. The addition of ketamine did not improve the analgesia or postoperative lung function. Increasing the dose of 
ketamine resulted only in an increased incidence of postoperative dreaming. However, our findings support previous studies $^{14,17}$ that the combination is useful, and has an increased analgesic effect.

One of the most troubling side effects of ketamine is the high incidence of adverse psychomimetic effects, with a reported range from $4 \%$ to $80 \% .{ }^{25,26}$ In our investigation, psychomimetic effects were clinically and statistically insignificant among our patients who received ketamine with their morphine. Only one patient receiving the ketamine-plus-morphine mixture reported dysphoria compared with three in the morphine-only group.

We have found that the combination of ketamine at low, sub-dissociative doses and morphine delivered via IVPCA is a safe and effective means of providing postoperative analgesia that deserves consideration as part of the postoperative pain control armamentarium.

\section{References}

1 Gross JB, Caldwell CB, Edwards MW. Induction doseresponse curves for midazolam and ketamine in premedicated ASA class III and IV patients. Anesth Analg 1985; 64: 795-800.

2 Amiot JF, Bouju P, Palacci JH, Balliner E. Intravenous regional anaesthesia with ketamine. Anaesthesia 1985; 40: 899-901.

3 Kitahata LM, Taub A, Kosaka $Y$. Lamina-specific suppression of dorsal-horn unit activity by ketamine hydrochloride. Anesthesiology 1973; 38: 4-11.

4 Dich-Nielsen JO, Svendsen LB, Berthelsen P. Intramuscular low-dose ketamine versus pethidine for postoperative pain treatment after thoracic surgery. Acta Anaesthesiol Scand 1992; 36: 583-7.

5 Hartvig P, Larsson E, Joachimsson PO. Postoperative analgesia and sedation following pediatric cardiac surgery using a constant infusion of ketamine. J Cardiothorac Vasc Anesth 1993; 7: 148-53.

6 Pekoe GM, Smith DJ. The involvement of opiate and monoaminergic neuronal systems in the analgesic effects of ketamine. Pain 1982; 12: 57-73.

7 Dowdy EG, Kaya K, Gocho Y. Some pharmacologic similarities of ketamine, lidocaine, and procaine. Anesth Analg 1973; 52: 839-42.

8 Domino EF, Chodoff $P$, Corssen $G$. Pharmacologic effects of CI-581, a new dissociative anesthetic, in man. Clin Pharmacol Ther 1965; 6: 279-91.

9 Bourke DL, Malit LA, Smith TC. Respiratory interactions of ketamine and morphine. Anesthesiology 1987; 66: 153-6.

10 Reich $D L$, Silvay G. Ketamine: an update on the first twenty-five years of clinical experience. Can J Anaesth 1989; 36: 186-97.

11 Corssen G, Guitierrez J, Reves JG, Huber FC Jr.
Ketamine in the anesthetic management of asthmatic patients. Anesth Analg 1972; 51: 588-96.

12 Slogoff S, Allen GW. The role of baroreceptors in the cardiovascular response to ketamine. Anesth Analg 1974; 53: 704-7.

13 Leunt LY, Baillie TA. Comparative pharmacology in the rat of ketamine and its two principal metabolites, norketamine and (2)-6-hydroxynorketamine. J Med Chem 1986; 29: 2396-9.

14 Bristow A, Orlikowski C. Subcutaneous ketamine analgesia: postoperative analgesia using subcutaneous infusions of ketamine and morphine. Ann R Coll Surg Engl 1989; 71: 64-6.

15 Grant IS, Nimmo WS, McNicol LR, Clements JA. Ketamine disposition in children and adults. Br J Anaesth 1995; 55: 1107-11.

16 White PF, Way WL, Trevor AJ. Ketamine - its pharmacology and therapeutic uses. Anesthesiology 1982; 56: 119-36.

17 Parkhouse J, Mariott G. Postoperative analgesia with ketamine and pethidine. Anaesthesia 1977; 32: 285-9.

18 Edwards ND, Fletcher A, Cole JR, Peacock JE. Combined infusions of morphine and ketamine for postoperative pain in elderly patients. Anaesthesia 1993; 48: 124-7.

19 Ferrente FM, Ostheimer GW, Covino BG. Patient characteristics influencing effective PCA, In: Ferrente FM, Ostheimer GW, Covino BG (Eds.). Patient Controlled Analgesia. Cambridge MA: Blackwell Scientific Publications: 1990: 51-60.

20 SPSS for Windows, Release 6.0. Chicago: SPSS, Inc. 1993.

21 Miyasaka M, Domino EF. Neural mechanisms of ketamine-induced anesthesia. Int J Neuropharmacol 1968; 7 : 557-73.

22 Corssen G, Reves JG, Stanley TH. Intravenous Anaesthesia and Analgesia. Philadelphia: Lea \& Febiger, 1988.

23 Winters WD, Hance AJ, Cadd GG, Quam DD, Benthuysen $J L$. Ketamine- and morphine-induced analgesia and catalepsy. I. Tolerance, cross-tolerance, potentiation, residual morphine levels and naloxone action in the rat. $J$ Pharmacol Exp Ther 1988; 244: 51-7.

24 Hance AJ, Winters WD, Quam DD, Benthuysen JL, Cadd $G G$. Catalepsy induced by combinations of ketamine and morphine: potentiation, antagonism, tolerance and cross tolerance in the rat. Neuropharmacology 1989; 28 : 109-16.

25 Fine J, Finestone SC. Sensory disturbances following ketamine anesthesia: recurrent hallucinations. Anesth Analg 1973; 52: 428-30.

26 Sadove MS, Shulman M, Hatano S, Fevold N. Analgesic effects of ketamine administered in subdissociative doses. Anesth Analg 1971; 50: 452-7. 